\title{
Regulation for Renewable Energy Development: Lessons from Sri Lanka Experience
}

\author{
Priyantha D C Wijayatunga \\ Asian Development Bank, Manila, Philippines \\ * Corresponding author. Tel: +6326326131, Fax: +6326362338, E-mail: pwijayatunga@adb.org
}

\begin{abstract}
The paper examines the key features of the small hydropower development environment in Sri Lanka which led to sector's rapid expansion. The recent development framework of the small hydropower sector was based on the importance of using indigenous resources, recognizing the positive environmental impacts and the avoidance of high cost alternative thermal generation. This framework also recognized the pioneering effort of the developers in site identification by giving rights to develop on a first-come first-served basis. The policy framework was later extended with a renewable energy portfolio standard to achieve $10 \%$ of power generation through renewable energy. The standard power purchase arrangements reduced the transaction costs. The feeding tariffs originally based on avoided costs later shifted to cost based, technology specific tariffs encouraging diversification of the renewable energy portfolio. The introduction of net-metering for renewable energy based distributed generation and the limited interventions in the form of green tariffs also assisted the renewable energy development. The paper concludes that the policy and regulatory frameworks and different approaches to implementing them have been mostly successful experiences in Sri Lanka and they would provide useful lessons for similar countries when formulating and implementing related polices, regulations and legal frameworks.
\end{abstract}

Keywords: Renewable energy, regulation, feed-in-tariff, avoided cost, net-metering

\section{Introduction}

Sri Lanka has a long history of using renewable energy for its power generation dating back to early $20^{\text {th }}$ century when most of the tea plantation companies installed small hydropower plants to provide their electricity needs. Since then, the country's power generation system gradually developed into a large hydropower dominated system until early 1990s when almost $100 \%$ of its supplies came from hydropower. With the exponentially increasing demand for electricity and due to limited large hydro resources the country turned to oil based thermal power plants to supply its base-load requirements. The small hydropower development, though impeded until 1980s due to penetration of the national grid and large hydropower domination, became an attraction, with the increasing fuel costs for thermal power generation.

The paper examines the key features of the framework for grid connected renewable energy and in particular small hydropower development in Sri Lanka and how the policy and regulatory interventions assisted the sector's rapid expansion.

\section{Policy Environment}

\subsection{Renewable Energy Development Policy}

In the mid 1990s there was a resurgence of the interest in small hydropower development, particularly on the grid connected power plants. The policy environment was developed by the government with the assistance of the Ceylon Electricity Board (CEB) which was the sole purchaser of power generated by outside its own generation system. This process involved, assigning sites for development, licensing and power purchase agreement. Later with the rapid development of the small hydropower sector, the need to facilitate expansion into other renewable energy sources led the government to specifically address these aspects in the energy policy being drafted in 2006/07. From the beginning, the government policy has been to allow the private sector to develop all grid-connected plants up to 10MW. 
The Energy Policy and Strategies of Sri Lanka has given due emphasis to the development of both the conventional and non-conventional renewable energy based generation (NCRE) [1]. One of the key policy elements is the promotion of indigenous resources in energy supplies. The relevant strategies have been identified in order to achieve this objective. They are the following

- The use of economically viable, environmentally friendly, non-conventional renewable energy sources to be promoted by providing a level playing field in generation sector development

- Concessionary financing to be sought to implement hydroelectric projects which are not viable under normal commercial terms

- Necessary incentives to be provided to other non-economic non-conventional renewable energy resources where appropriate to ensure their contribution to the energy supply

- A separate facilitation centre dedicated to the systematic planning and promotion of nonconventional renewable energy sources will be established.

- Appropriate steps to be taken to ensure the development and efficient use of noncommercial energy supplies such as biomass.

- Research and development on adopting new technologies and practices to be promoted

The policy has identified small hydropower, biomass power and wind energy as the three leading non-conventional forms of renewable energy sources to be promoted in Sri Lanka for grid connected electricity generation. The Government would endeavour to reach a level of $10 \%$ of grid electricity generated to be produced using NCRE by 2015 . Though this policy has not yet been formally translated into a renewable energy portfolio standard issued by the regulator, the government and the regulator are taking necessary measures to reach this target.

The government has recognized the principle that the natural resources are public goods and hence the associated benefits need to be passed on to all the citizens in the country. But in the interest of expanding the NCRE technology penetration no resource cost is charged for a period of 12 years from the date of commercial operation. The resource charges will be used to finance incentives for further NCRE development through the Energy Fund. Therefore this recent development framework for renewable energy sources within which the small hydropower sector operates was based on the importance of using indigenous resources while recognizing the positive environmental impacts and the avoidance of high cost alternative thermal generation.

\subsection{Institutional Framework}

During the initial development phase of the small hydropower sector, CEB was the main institution involved as the sole purchaser of electricity generated by these plants. Central government agencies and provincial and local authorities have been involved in the areas such as land acquisition, environmental clearance and water rights. Once after commissioning the plant, apart from licensing and notifying the annual power purchase tariff determined by $\mathrm{CEB}$, the central government's role in the sector was minimal.

With the expansion of the small hydropower sector and the interest of the private sector in developing other renewable energy sources, the government strongly felt the need to have a dedicated agency with adequate authority for NCRE resource development. Not only this agency needed to be able to facilitate the process of NCRE development but also it was to have the statutory powers to intervene and overcome barriers. Addressing this requirement the Government passed a new legislation to establish the Sustainable Energy Authority (SEA) 
in 2007 [2]. The board of directors of SEA has the representation from all important stakeholder state agencies and the private sector. This has enabled SEA to address many of the critical issues within their board meetings.

\subsection{Site Selection and Development}

The CEB developed the hydropower master plan in 1989 which identified many of the hydropower development sites greater than 1MW capacity [3]. In addition, independent investigations by prospective developers and interested individuals and groups also have led to identification of many sites for small hydropower development including those below 1 MW capacity. The government policy has been to allow private sector to be the sole developer of all the sites below 10MW capacity connected to the national grid. The right to develop each of the sites has been awarded on a first-come first-served basis through a letterof-intent offered by the CEB, recognizing the pioneering effort of the developers in site identification. Later, in order to avoid excessive delays in developing sites for which the letters-of-intent have been issued, the government decided to impose a time limit for development activities to start and progress. If no progress is made within the timeframe provided the letter-of-intent for the relevant site is withdrawn.

During the development of the grid-connected small hydropower sites, the developers usually respond to the needs of the local population partly advocated by the local government bodies in order to ensure smooth implementation. Such interventions by the developers include those such as construction of paved access roads and bridges in the surrounding rural areas which improve transport facilities for the rural communities. In addition, local manpower and other resources are used to the maximum during construction and operation of the plants.

The off-grid micro-hydropower sites often identified by rural communities have been developed by the community organizations themselves, with the assistance of some nongovernmental organizations. The community contributes both in-kind through manpower and material for construction and operation of the plants and in cash. These micro-hydro plants have varying capacities ranging from $5 \mathrm{~kW}$ to $25 \mathrm{~kW}$ each serving $25-200$ village households depending on the capacity.

\section{Regulatory Environment}

The regulatory environment for small-hydropower involves licensing, power purchase agreements and feed-in tariffs. In the initial stages of development the institutions involved in this regard were the Ministry of Power and Energy and the CEB. With the establishment of the Public Utilities Commission of Sri Lanka (PUCSL) in 2003 and the enactment of the Sri Lanka Electricity Act of 2009, the regulatory authority over the small-hydropower sector fell within the purview of the PUCSL.

\subsection{Standardized Power Purchase Agreement}

In 1997 CEB introduced a standardized power purchase agreement (SPPA) for small gridconnected renewable energy based electricity generating plants less than 10MW. SPPA binds the CEB to purchase power generated by these plants without a limitation at a tariff declared every year. Further, the generator was assured a minimum tariff of $90 \%$ of tariff in the first year of its commissioning, throughout the SPPA duration. 


\subsection{Feed-in Tariffs}

\subsubsection{Avoided Cost Based}

In 1997/98 the government declared that the SPPA tariff would be based on the "avoided cost” principle. The tariff calculated as the three year moving average was published at the beginning of each year. Initially the avoided cost was determined using the long term generation planning model which derives the generation expansion plan for the country for the following 20 years. It is a rolling plan and the calculation methodology captured the long term impact of the addition of renewable energy based small power plants in the overall long term generation plan. Later with the understanding between the CEB and developers the methodology was shifted to the operational planning model used in the system control centre where the short term operational costs provided the key inputs to the calculation process [4].

\subsubsection{Project Cost based}

In 2007/08 the government took a decision to reexamine the feed-in tariff regime as a part of the new energy policy where specific renewable energy targets are to be achieved by 2015 . This process led to the introduction of the technology specific cost based feed-in tariffs for all types of renewable energy based plants which would be developed. Initially these renewable energy sources were limited to small-hydropower, wind and biomass. The tariff is designed to make sure that the developer would always have positive cash flow during the SPPA period. The tariff is revised periodically to ensure gradual penetration of different technologies. This new tariff is expected to encourage wind and biomass based plants which tend to have costs higher than those can be recovered through avoided cost based tariff. The plants already in operation or those in which SPPAs had been signed were given the option to remain in the previous tariff regime or to switch to the new regime.

\subsubsection{Green-Power Tariff}

In 2008 PUCSL initiated action on the allowing interested consumers to purchase power from identified NCRE based power plants. Though direct power wheeling from the generators to the users has not been legally permitted under the electricity act, PUCSL could encourage green-power consumers to enter into agreements with the generators to pay an additional charge directly for the power delivered while paying the standard consumer tariff to the CEB. PUCSL annually verifies whether the energy delivered to the consumers by such generators would satisfy their annual consumption expectation of green-power as agreed in advance. Accordingly, the final payments are reconciled.

\section{3. $\quad$ Net-metering}

On the advice of SEA, government and the CEB agreed for net-metering of premises with NCRE based systems connected to the grid in 2009. Though the feed-in tariff is not offered to these systems unless they have an SPPA, these premises can still use the grid as an energy storage. If systems are properly designed, net-metering now opens the door for such premises to be carbon neutral in their power consumption.

\subsection{Exemptions from generation license}

In the initial stages of development, off-grid generators never used to obtain generation (and distribution) license which is required under the law. The authorities ignored this situation considering that the requirements to fulfill for generation license are too cumbersome for the community operated small off-grid systems to fulfill, though operating these systems without a license was in contravention to the Electricity Act. When the PUCSL became empowered 
with regulatory authority over the power sector in 2009, under the provisions of the Sri Lanka Electricity Act it has been taking steps to exempt off-grid generators from licensing.

\section{Analysis and Discussion}

\subsection{Policy}

The government policy of working towards an NCRE development target by 2015 has helped the SEA, CEB and the PUCSL to justify incentives for NCRE development. This can be in the form of direct government subsidies or cross-subsidies in the sector.

The policy of allowing private sector to develop all grid-connected power plants below $10 \mathrm{MW}$ and offer of an standardized power purchase agreement with guaranteed unlimited power purchase at a predictable price have encouraged both local and foreign investors to enter into the small hydropower sector. The sector was further attracted by the investors due to the policy of offering sites on a first-come first-served basis which incentivized rapid site identification, investigation and development. The resulting exponential development since 1998 can be seen in figures 1 and 2 where NCRE development up to 2008 has been totally dominated by small hydropower.

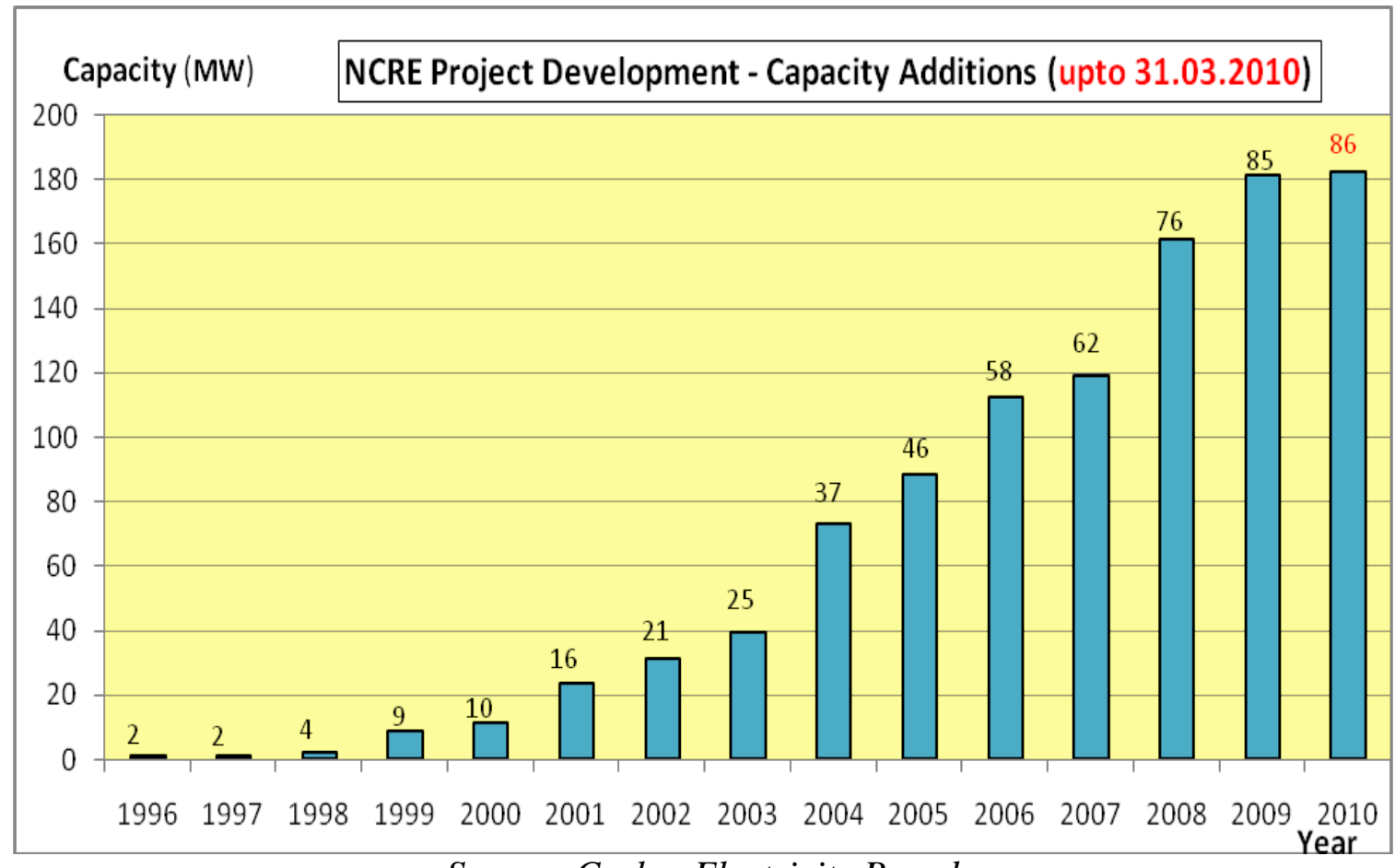

Source: Ceylon Electricity Board

Fig. 1. Total Capacity Additions of Non-Conventional Renewable Energy Based Generation

During the initial stages, the rights to develop the sites were obtained by those who actually wanted to invest in the projects. As the sector development gathered momentum, interested parties used the prevailing policy of site allocation to obtain the right to develop the site and sell the rights to other investors. This created an unhealthy market for letters-of-intent for small hydropower sites which eventually increased the effective project costs and delayed development. This situation was arrested to a certain extent with the introduction of a time limit for development where the investment needed to be in place within a specific time frame. 
The optimal capacity of the power plant to be constructed at given site is a function of the investment and the returns it brings based on the hydrological conditions. As a result of the investors being allowed to choose the capacity of the plants to be constructed, the plant capacity became a function of available financing. This has resulted in under-sizing of plant capacity in certain sites leading to an economic loss. This situation could have been avoided if the utility or the SEA carried out an independent assessment and incentivized the developers to construct the plants to their optimal capacity.

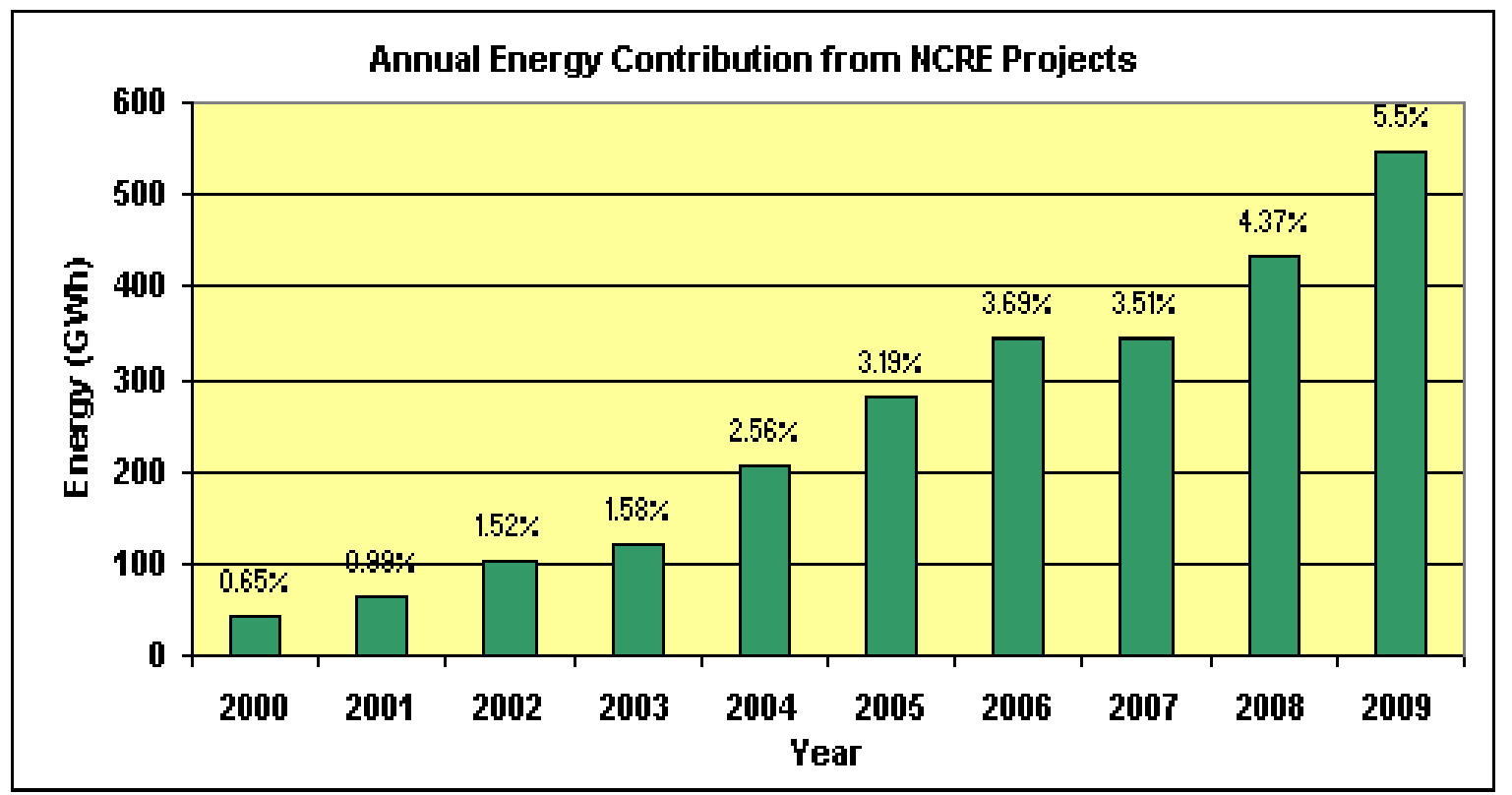

Source: Ceylon Electricity Board

Fig. 2. Total Energy Supply from Non-Conventional Renewable Energy Based Generation

\subsection{Regulation}

The feed-in tariff based on the avoided cost of generation provided significant returns to the investors of small hydropower plants, in the initial phase of development where most of the better sites had been developed. Since during this initial period the avoided cost calculation was based on the long term generation plan, the feed-in-tariff was linked to the most economical generation expansion in the country. But this hardly reflected the actual situation on the ground where the CEB could not follow this plan due to external interventions. This led to the avoided cost calculation being shifted to the operational plan where short term generation schedule was the key input to the calculation. Since the generation system has been suboptimal the avoided cost determined in this manner provided even a higher feed-intariff. This environment attracted more investors to the small hydropower sector since even less economically efficient sites could be now developed while the more economically efficient sites led to significantly large returns to the investors. With this approach to feed-intariff, the benefit of low cost hydropower was never passed on the final electricity consumer nor it did not assist development of other NCRE sources such as wind and biomass.

With the introduction of the cost based feed-in-tariff the small hydropower sector provided savings which could be used to subsidize other more expensive technologies such as wind and biomass while still providing adequate returns to the investors in small hydropower sector. Also it reduced the financial burden on the government and the final electricity consumers due to addition of these expensive plants. 
Green-power transactions facilitated by the PUCSL opened a new approach to supplying green-power to the interested consumers within the existing legal framework where power "wheeling" is not allowed. This enables, particularly green manufacturing which is fast becoming an important export oriented sector, to expand. Net-metering arrangements can further enhance these opportunities for the green-power generation and consumption.

\section{Conclusions}

The paper discussed the experience in the policy and regulatory environment in the Sri Lanka renewable energy sector. This included the areas such as renewable energy targets, institutional mechanisms, renewable energy site selection and allocation, feed-in tariffs and green-tariffs.

The paper concludes that the policy and regulatory frameworks and different approaches to implementing them have been mostly successful experiences in Sri Lanka. These along with less successful experiences would provide useful lessons for similar power systems in other countries when formulating and implementing related polices, regulations and legal frameworks leading to accelerated development of the renewable energy industry.

\section{References}

[1] Energy Policy and Strategies of Sri Lanka, Ministry of Power and Energy, 2009

[2] The Priyantha D.C. Wijayatunga, Darshana Prasad, Clean energy technology and regulatory interventions for Greenhouse Gas emission mitigation: Sri Lankan power sector, Energy Conservation and Management, 50, 2009, pp 1595-1603

[3] Master Plan for the Electricity Supply of Sri Lanka, Ceylon Electricity Board Sri Lanka, 1989

[4] Resource Management Associates (Pvt.) Ltd. Study on grid connected small power tariff in Sri Lanka. Final Report, Resource Management Associates (Pvt.) Ltd., No. 3, Charles Terrace, Colombo 3, Sri Lanka, 2001. 